\title{
VEGETATION AND WARM CLIMATES DURING THE LATE CRETACEOUS
}

UPCHURCH*, Garland R., Jr., Department of Biology, Southwest Texas State University, San Marcos, TX 78666, U.S.A.; OTTO-BLIESNER, Bette, Climate Change Section, National Center for Atmospheric Research, Boulder, CO 80307 U.S.A.; SCOTESE, Christopher, Department of Geological Sciences, University of Texas, Arlington, TX 76019 U.S.A.

Mechanisms for maintaining warm temperatures at high latitudes and in continental interiors during the Cretaceous are incompletely understood. Previous model simulations implicate paleogeography, increased atmospheric $\mathrm{CO}_{2}$, and increased ocean heat transport as mechanisms of high-latitude warmth. However, published model simulations that incorporate these factors cannot reproduce the summer and winter warmth indicated by temperature proxies such as fossil plants. This could indicate model deficiencies or the lack of at least one important factor in model simulations.

Vegetation--a factor not considered in previously published simulations of Cretaceous climate--alters the properties of the land surface, especially absorption of solar radiation and the transfer of heat and momentum between the land surface and the atmosphere. Simulations of Holocene and future climates indicate that areal increases in forest vegetation can significantly warm high latitudes. The simulated effect of high-latitude vegetation is equivalent to a doubling of $\mathrm{CO}_{2}$ or orbital forcing.

The potential importance of vegetation in maintaining warm Cretaceous climates was evaluated in a three-part analysis: 1) construction of a global data base of Maastrichtian indicators for paleoclimate and paleovegetation, 2) simulation of latest Cretaceous climates with the land-surface coded as bare soil, evergreen rainforest, or realistic vegetation, and 3) comparison of model output with the global data base of paleoclimatic indicators. Model simulations use the GENESIS Earth Systems Model, version 1.02 , which simulates the physical effects of vegetation on the land surface. The global data base of Maastrichtian climatic indicators includes plant megafossils, select palynological environmental indicators, and lithologies such as coals, evaporites, and calcretes. Atmospheric $\mathrm{CO}_{2}$ was set to $580 \mathrm{ppm}$. Ocean heat transport was set to modern values.

Maastrichtian paleovegetation reflects the warmth of Late Cretaceous climates. The Arctic and Antarctic supported areally extensive forests, which were deciduous in the Arctic. Middle latitudes supported broad-leaved evergreen woodlands or forests with little or no winter freezing. Deserts were present in southern Asia, Africa, and South America. Tropical rainforest was restricted to narrow bands along the equator.

High latitudes show greater sensitivity to vegetation cover than low latitudes in model simulations. Inclusion of vegetation in simulations increases congruence with paleoclimatic indicators. The bare soil simulation incorrectly predicts tundra for large areas of Siberia and North America. In contrast, evergreen forest and realistic vegetation simulations correctly predict extensive forests for the Arctic and Antarctic. Areally extensive forest vegetation warms average global surface temperatures by over $3^{\circ} \mathrm{C}$ : the tropics warm less than $2^{\circ} \mathrm{C}$, while the high latitudes warm by up to $15^{\circ} \mathrm{C}$. Simulations with realistic vegetation show the fewest discrepancies with climatic proxies in respect to summer temperature and precipitation. However, simulated winter temperatures are still too cold in parts of North America. This may indicate unrealistically low levels of $\mathrm{CO}_{2}$ or ocean heat transport in the simulations, or the need to include additional factors. 